\title{
Histologia da medula óssea
}

\section{Bone marrow histology}

Antonio C. Alves

\section{Introdução}

A biópsia de medula óssea, anteriormente restrita a hospitais e laboratórios especializados em Hematologia e Oncologia, atualmente faz parte da rotina de laboratórios de Anatomia Patológica privados. Tal mudança foi devida à simplificação na obtenção do material: as biópsias cirúrgicas em cunha ou curetagem foram substituídas pelas biópsias com agulha, realizadas em ambulatórios ou consultórios e com risco praticamente nulo. O mielograma preserva indiscutivelmente as características citológicas minuciosas das células hematopoéticas e permite estudo citoquímico completo. A biópsia, entretanto, permite avaliar a quantidade do tecido hematopoético, estudar o tecido conjuntivo e identificar comprometimentos neoplásicos - metástases, linfomas Hodgkin e não Hodgkin - que poderiam não ser detectados em esfregaços.

\section{Coleta do material}

A agulha mais utilizada é a de Jamshidi, introduzida em 1971. A biópsia, preferencialmente, é executada em crista ilíaca posterior, obtendo-se um cilindro com diâmetro dependendo da agulha utilizada (em torno de $2 \mathrm{~mm}$ ) e comprimento de acordo com a profundidade da biópsia, em torno de 20 a 30 mm.

\section{Processamento do material}

Obtido o cilindro da medula óssea, é conveniente a realização de esfregaços em lâminas e dessecação ao ar para, se necessário, corarmos com corantes utilizados em hematologia e obtermos os detalhes citológicos que escapam ao material fixado e processado em parafina. A fixação pode ser realizada com formol tamponado a 10\%, Bouin, Dubosq-Brazil, Zenker, B5 e outros. É importante ressaltar que o fixador de escolha depende de características próprias de cada laboratório. Algumas misturas fixadoras têm custo mais elevado além de utilizarem substâncias venenosas, como o bicloreto de mercúrio, ou substâncias cuja aquisição é extremamente controlada, como o ácido pícrico. O tempo de fixação é tão importante quanto o fixador, devendo ser de, no máximo, 24 horas no formol, entre 4 a 12 horas no Dubosq-Brazil e Bouin e de 4 horas no Zenker e B5. A descalcificação deve ser cuidadosa podendo ser utilizado o EDTA preferencialmente

Professor Adjunto do Departamento de Patologia da Unifesp - Escola Paulista de Medicina - São Paulo-SP.

Responsável pelo setor de Patologia do Diagnósticos da América S/A - São Paulo-SP.

Escola Paulista de Medicina - Unifesp - São Paulo-SP.

Diagnósticos da América S/A - São Paulo-SP.

Correspondência: Antonio Corrêa Alves

Av. Sabiá, 399 ap $101-$ Moema

04515-000 - São Paulo-SP - Brasil

Cel: (55 11) 9102-5264; Res: (55 11) 5051-7956

E-mail: acalves@unifesp.bre antalves@uol.com.br

Doi: 10.1590/S1516-84842009005000049 
ou o ácido nítrico a 5\% ou 8\% no máximo durante uma noite. Bons resultados são obtidos com descalcificação por ácido nítrico a $8 \%$ durante três horas. Tanto a fixação como a descalcificação são pontos críticos e devem ter a atenção redobrada para que haja conservação antigênica permitindo estudo imuno-histoquímico posterior. A lavagem com água corrente abundante é seguida pelo processamento de rotina para inclusão em parafina. A inclusão em matéria plástica, apesar de fornecer morfologia de qualidade superior, tem em seu custo mais elevado uma forte contraindicação.

\section{Colorações}

As colorações pelo HE, Giemsa, reticulina, PAS, Perls e tricrômio são fundamentais e as três primeiras indispensáveis. A reticulina deve ter especial atenção, pois o aumento da mesma está associado às metástases, infiltrações linfomatosas e doenças hematopoéticas.

\section{Morfologia normal}

1 - Série eritrocítica ou eritroide - Os eritroblastos são células com núcleos redondos e cromatina densa, circundados por citoplasma mais ou menos abundante, basofílico ou acidofílico (Figura 1). O halo claro de citoplasma nestas células é artefato devido à fixação por formol, porém é útil na identificação das mesmas e no diagnóstico diferencial com linfócitos que não o apresentam. Dispõem-se em agrupamentos denominados ilhotas eritroblásticas, onde também podem ser encontradas células com núcleo maior contendo um ou dois nucléolos e citoplasma basofílico - os proeritroblastos precursores (Figura 2). No centro das ilhotas eritroblásticas pode ser identificado um macrófago com prolongamentos citoplasmáticos envolvendo os eritroblastos e eventualmente contendo hemossiderina revelável pelo método de Perls.

2 - Série granulocítica ou mieloide - As células da série granulocítica ou mieloide não se dispõem em grupos tão nítidos como os da série eritroide, sendo, portanto, mais difíceis de serem identificadas. As granulações são também menos visíveis nas biópsias do que nos esfregaços. As células

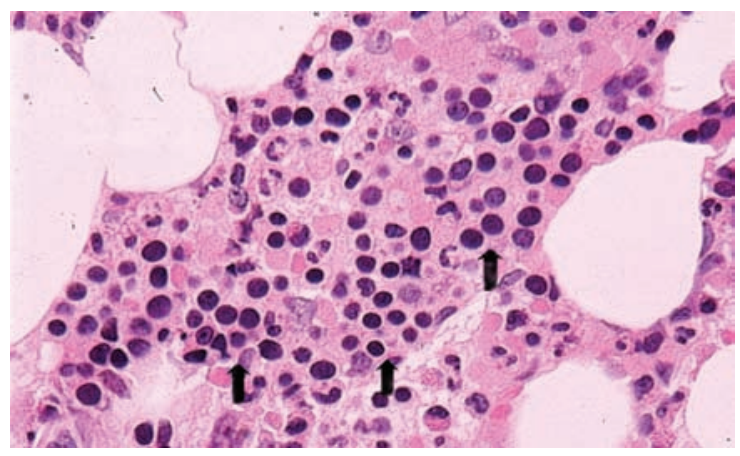

Figura 1. Ilhotas eritroblásticas típicas. ((HE 400X) imaturas dispõem-se junto às trabéculas ósseas e a maturação ocorre no centro das cavidades (Figura 3). Os mieloblastos são semelhantes aos proeritroblastos tendo as mesmas dimensões e aspectos morfológicos, núcleo contendo um ou dois nucléolos e citoplasma basofílico,

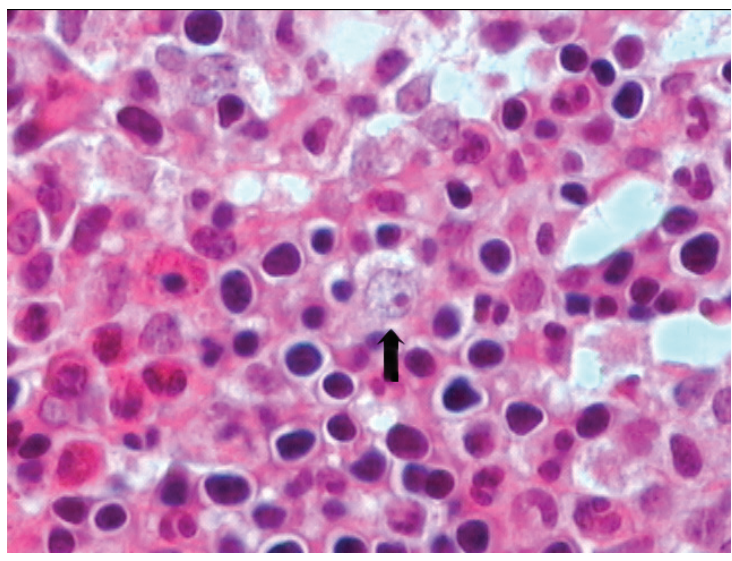

Figura 2. Ilhota eritroblástica com proeritroblasto em posição central, indicado na seta (HE 630X imersão)

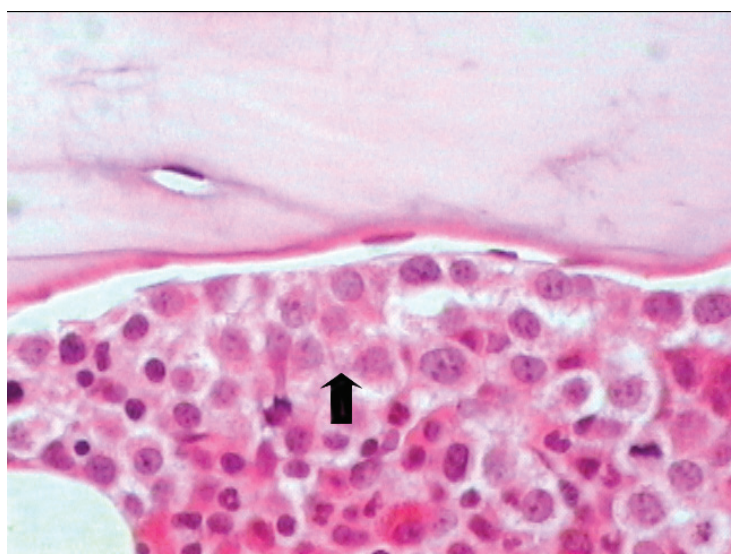

Figura 3. Precursores mieloides junto à trabécula óssea (HE 630X imersão)

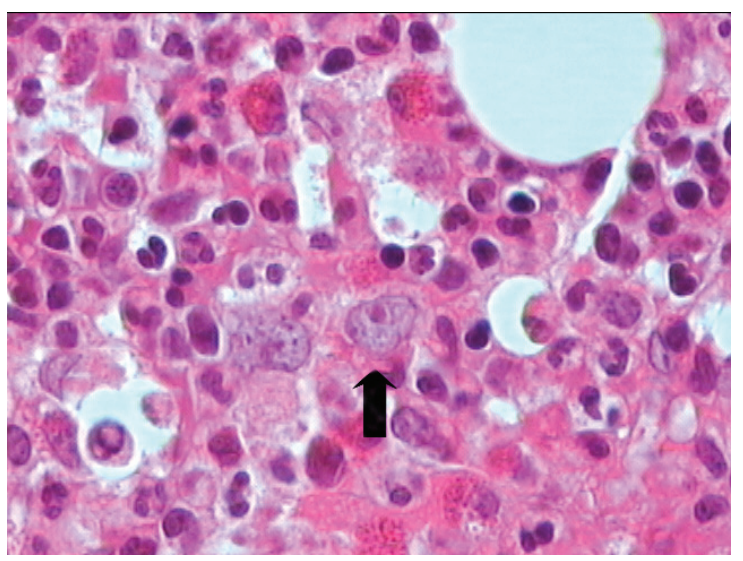

Figura 4. Mieloblasto no centro da foto (HE 630X imersão) 
sendo difícil sua separação (Figura 4). Os promielócitos têm núcleo excêntrico, claro, com um ou dois nucléolos e alguns grânulos citoplasmáticos (Figura 5). Os mielócitos são células agrupadas, com núcleos excêntricos arredondados ou ovalados, pequeno nucléolo e citoplasma granuloso (Figura 6). Os metamielócitos têm núcleo lobulado (Figura 7) e os polimorfonucleares são reconhecidos pelo núcleo polilobulado (Figura 7). As granulações citoplasmáticas são bem evidenciadas pela coloração de Giemsa e também fechando o diafragma de campo. A proporção de células da série granulocítica em relação à série eritrocítica, proporção G:E, em medulas normais varia de 1,5:1 a 3:1.

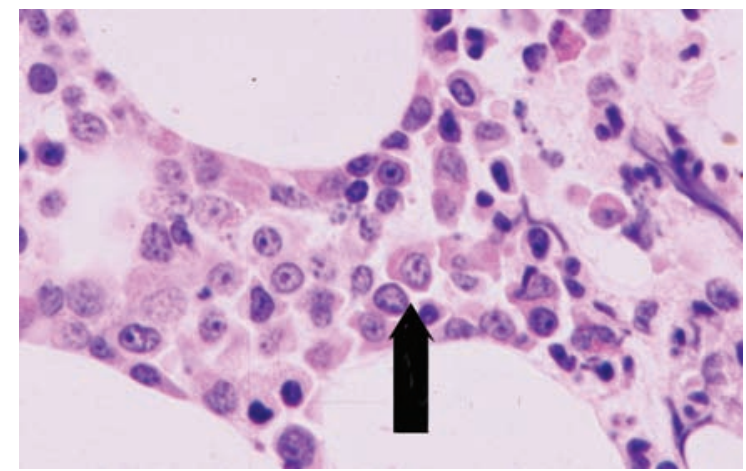

Figura 5. Promielócito na ponta da seta. (Giemsa 630X imersão)

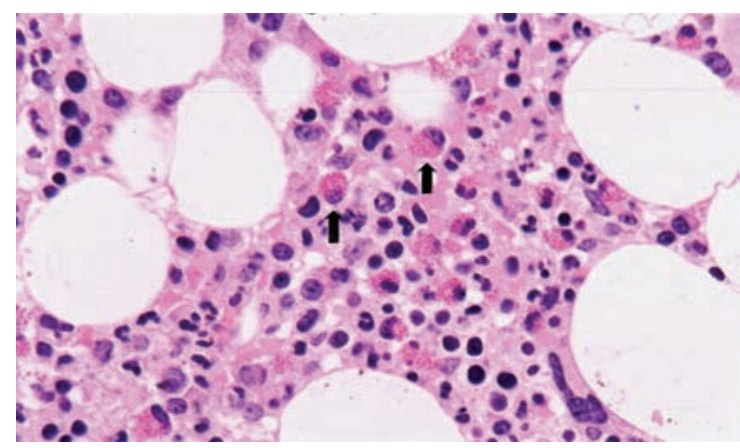

Figura 6. Mielócitos indicados nas setas (HE 400X)

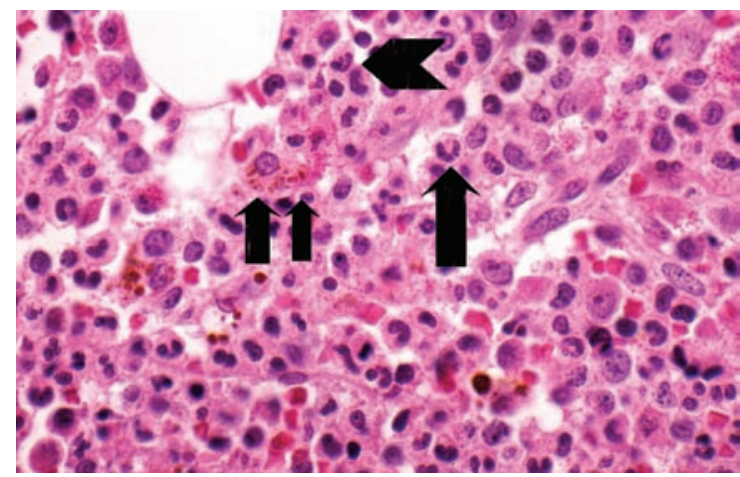

Figura 7. Metamielócito indicado na seta maior, polimorfonuclear na menor e histiócito com pigmento férrico na seta dupla (HE 400X)
3 - Série megacariocítica ou megacariocitária - Os megacariócitos são as células mais fáceis de serem reconhecidas em virtude de seu grande tamanho. Apresentam núcleo polilobulado desprovido de nucléolo, citoplasma homogêneo eosinófilo e são PAS positivos (Figura 8). Em número de um a dois até quatro por cavidade medular situamse junto aos seios venosos, dispostos isoladamente.

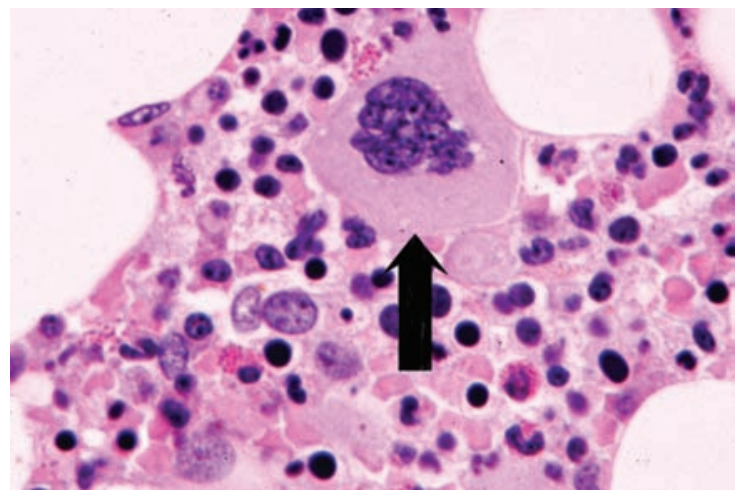

Figura 8. Megacariócito maduro típico (HE 630X imersão)

4 - Série monocítica ou monocitária - Os monócitos são maiores que os neutrófilos, com núcleo lobulado, e suas células precursoras não são reconhecidas em biópsias. Estão presentes em pequeno número nos indivíduos normais, localizados próximo às arteríolas, no centro dos espaços medulares.

5 - Histiócitos - São células difíceis de serem reconhecidas a não ser que contenham inclusões citoplasmáticas fagocitadas (Figura 9). Pouco numerosos, situam-se no centro dos cordões medulares, onde são circundados por eritroblastos, ou na parede dos seios venosos e, às vezes, contendo pigmento férrico revelável pela técnica de Perls. É importante ressaltar que a descalcificação diminui muito a quantidade de pigmento férrico.

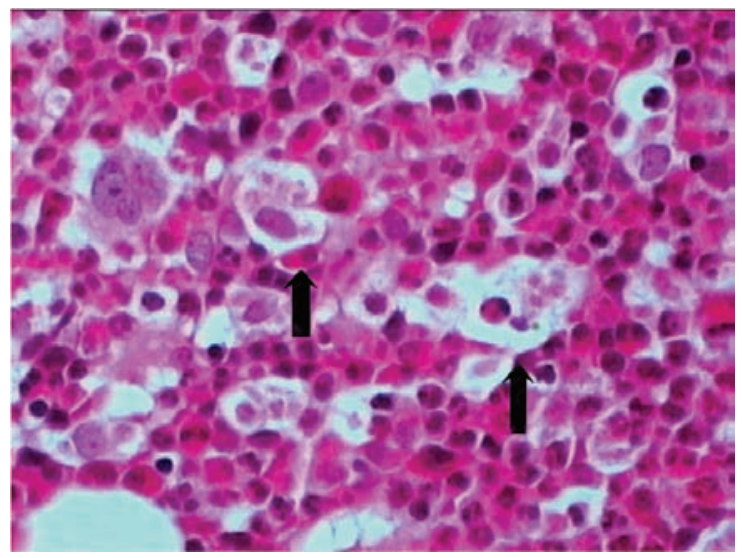

Figura 9. Histiócitos com corpos apoptóticos (HE 630X imersão) 
6 - Plasmócitos - Normalmente são encontrados em pequeno número e situam-se junto aos capilares arteriais. A morfologia clássica com núcleo redondo, cromatina agrupada junto à membrana nuclear, citoplasma basofílico e halo claro perinuclear tornam sua identificação fácil (Figura 10). Os mielócitos e os mastócitos, num exame superficial, podem assemelhar-se aos plasmócitos.

7 - Linfócitos - Apesar de sua morfologia facilmente reconhecível, são difíceis de serem identificados por serem em pequeno número e espalhados entre as outras células. $\mathrm{O}$ diagnóstico diferencial principal é com os eritroblastos, lembrando que estes têm o halo claro citoplasmático e os linfócitos têm cromatina mais organizada. Nas medulas normais podem ser encontrados em nódulos linfoides, entretanto, são sempre pouco numerosos e constituídos por pequenos linfócitos maduros, raramente com centros germinativos claros contendo histiócitos. Localizam-se no centro das cavidades e são delimitados por discreta rede de reticulina (Figura 11).

8-Mastócitos - Nas medulas normais são encontrados em pequeno número, apresentam citoplasma eosinófilo, granuloso, núcleo redondo, excêntrico, com cromatina densa. O citoplasma é PAS positivo e a coloração de Giemsa dá aspecto de mancha azul (Figura 12). Situam-se ao lado dos vasos, trabéculas ósseas e nódulos linfoides.

9 - Células adiposas - Representam um constituinte importante da medula óssea e são utilizadas comparativamente para avaliar a quantidade de tecido hematopoético na medula normal. Sua morfologia simples não representa dificuldade na identificação. A quantidade do tecido adiposo aumenta com a idade e é o elemento predominante no idoso.

10 - Fibras reticulares e colágenas - As fibras reticulares evidenciadas pelas impregnações argênticas, formam uma rede muito frouxa e pouco evidente, sendo que algumas fibras delimitam os seios venosos e algumas células

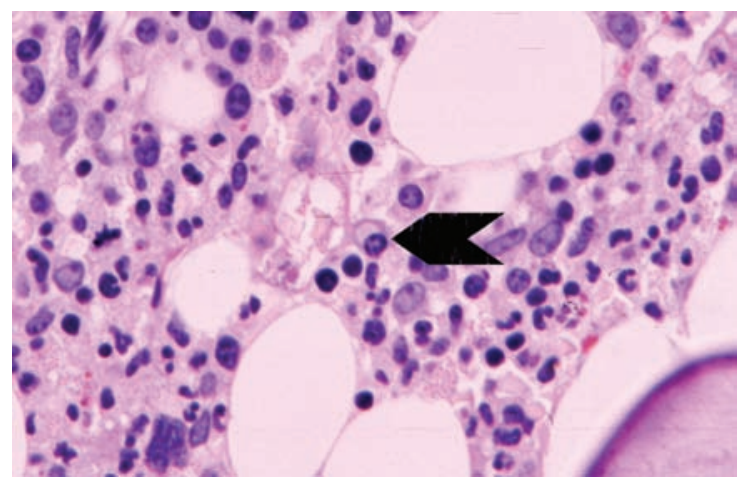

Figura 10. Plasmócito com halo claro perinuclear característico indicado pela seta (HE 630X imersão) adiposas. As fibras colágenas na medula normal praticamente não existem e situam-se em pequeno número em torno dos vasos maiores. A quantidade de reticulina e fibras colágenas é graduada segundo Bauermeister (Tabela 1) em: grau 0 - ausência de reticulina; grau 1 - fibras finas e esparsas ou rede focal (Figura 13); grau 2 - rede de fibras finas na maior parte do fragmento, ausência de fibras grossas (Figura 14); grau 3 - rede difusa de fibras finas com fibras grossas esparsas e ausência de colagenização (Figura 15) e grau 4 - rede difusa de fibras grossas com colagenização (Figura 16). Os graus 0 e1 são considerados como dentro da normalidade.

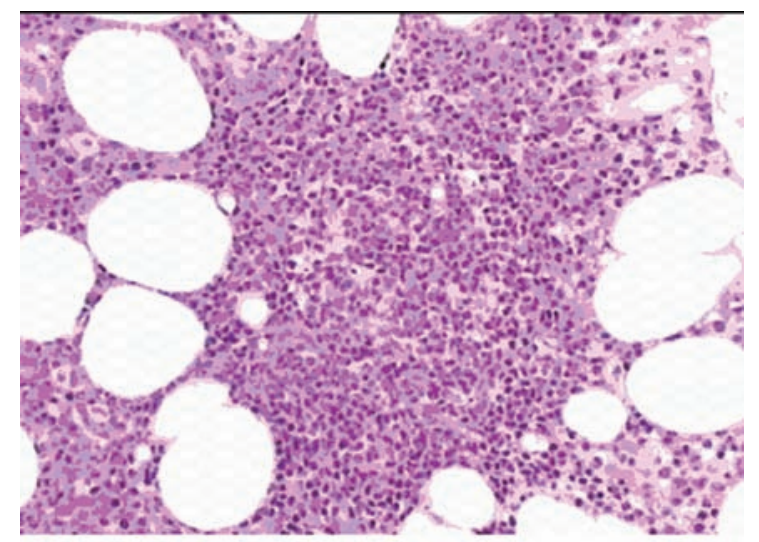

Figura 11. Nódulo linfoide de tipo reacional (HE 200X)

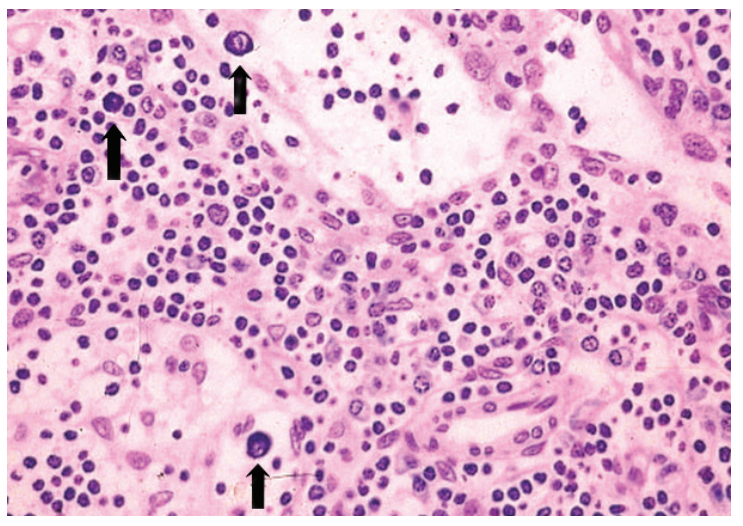

Figura 12. Mastócitos indicados nas setas (Giemsa 400X)

Tabela 1. Graduação de Bauermeister para reticulina e fibras colágenas

Grau 0 ausência de reticulina

Grau 1 fibras finas e esparsas ou rede focal

Grau 2 rede de fibras finas na maior parte do fragmento, ausência de fibras grossas

Grau 3 rede difusa de fibras finas com fibras grossas esparsas e ausência de colagenização

Grau 4 rede difusa de fibras grossas com colagenização 
11 - Tecido ósseo - As trabéculas ósseas estão presentes normalmente nas biópsias sendo também avaliadas quanto às características da matriz e suas células constituintes: osteoblastos, osteócitos e osteoclastos.

É importante ressaltar que em torno de $15 \%$ a $20 \%$ das células hematopoéticas não podem ser classificadas com precisão nas biópsias incluídas em parafina.

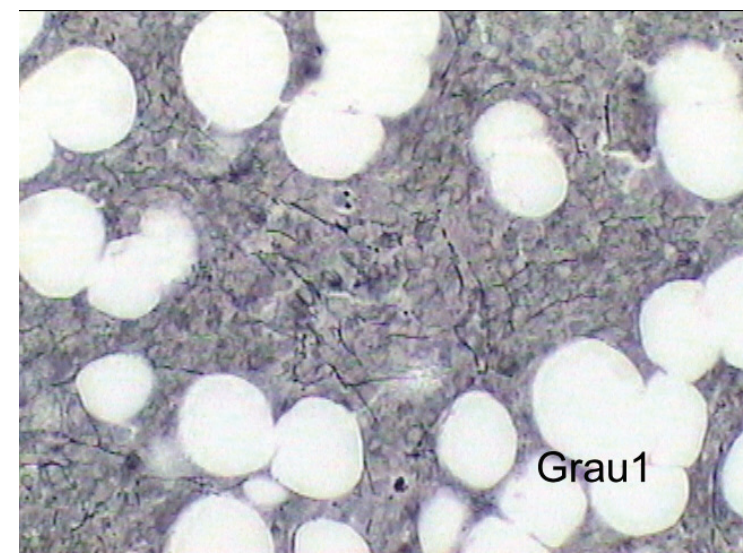

Figura 13. Reticulina grau 1 (Gomori 400X)

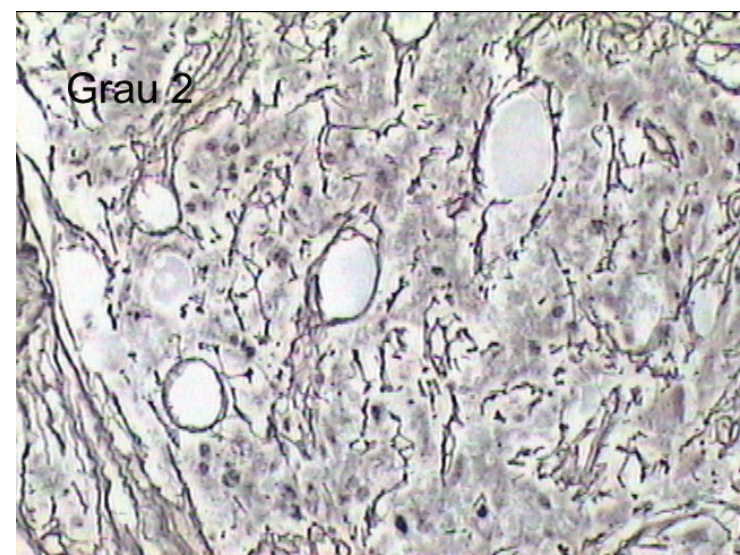

Figura 14. Reticulina grau 2 (Gomori 400X)

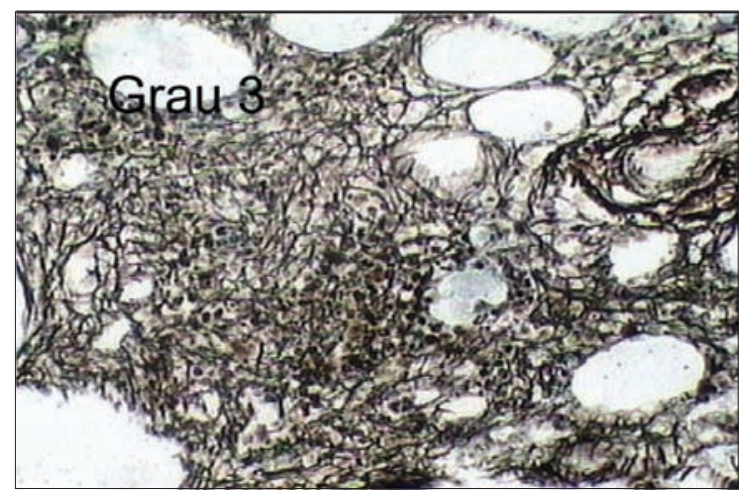

Figura 15. Reticulina grau 3 (Gomori 400X)

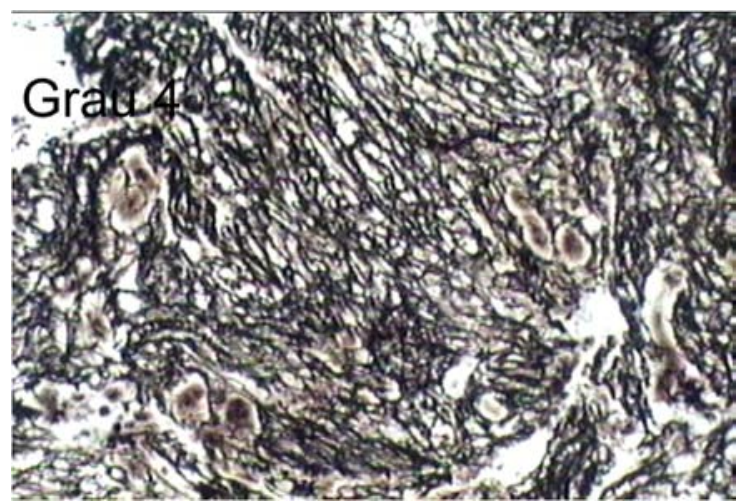

Figura 16. Reticulina grau 4 (gomori 400x)

Tabela 2. Quantidade de tecido hematopoético nos espaços medulares em relação ao tecido adiposo, seg. Hartsock criança

até os 35 anos

35 a 60 anos

após os 65 anos
$80 \%$ ou $90 \%$

mais de $50 \%$

em torno de $50 \%$

\section{Avaliação quantitativa do tecido hematopoético}

A celularidade da medula óssea depende da idade e Hartsock distingue três fases de involução: 1) até os 35 anos o tecido hematopoético ocupa mais de $50 \%$ dos espaços medulares, chegando a $80 \%$ ou $90 \%$ na criança; 2 ) de 35 a 60 anos é em torno de 50\%; e 3) após os 65 anos é inferior a $40 \%$ (Tabela 2). A quantidade do tecido hematopoético é expressa como porcentagem aproximada em relação ao tecido adiposo dentro da cavidade medular.

\section{Princípios de técnicas especiais}

O exame imuno-histoquímico é atualmente um poderoso instrumento diagnóstico, especialmente em biópsias de medulas ósseas, para identificação de neoplasias primárias, metastáticas e doenças específicas do tecido hematopoético. Entretanto, é perfeitamente conhecida a dificuldade técnica para a execução de reações em tecidos fixados e descalcificados por muito tempo. As técnicas atuais de recuperação antigênica permitiram, porém, a solução de grande parte desses problemas. A lista de antígenos a serem pesquisados na medula óssea é muito extensa e depende dos tipos celulares e doenças que necessitam identificação. Alguns devem ser lembrados: 1) mieloperoxidase, lisozima, glicoforina e CD34 para doenças hematopoéticas, 2) CD20, CD79a, CD10, CD5, CD3, bcl2, TdT, CD15, CD30 e ALK para linfomas Hodgkin e não Hodgkin, 3) cadeias kappa, lambda e CD138 para plasmocitomas e 4) uma lista grande de citoqueratinas, 
antígenos de células mesenquimais e outros marcadores tumorais específicos para pesquisa de neoplasias metastáticas.

\section{Conclusão}

O conhecimento da histologia normal da medula óssea é fundamental para a interpretação das biópsias e emissão de um laudo anatomopatológico. O critério comparativo é o principal, tendo sempre em mente as variações morfológicas evolutivas com a idade, os compartimentos celulares envolvidos e a análise conjunta com outros dados clínicos e laboratoriais. O laudo anatomopatológico não é um elemento isolado e, sim, faz parte do aspecto multidisciplinar para o diagnóstico correto.

\section{Abstract}

The bone marrow biopsy after the introduction of the Jamshidi needle has come into a routine practice due to the facilitation to obtain good sample. Due to the adequate size of the sample, the decalcification time decreased and consequently the histological quality improved allowing to the pathologist a more deep and precise morphological interpretation and diagnosis of the hematological and non-hematological disorders. For a correct diagnosis, the pathologist should be acquainted with the normal histology of the bone marrow parenchyma, it variations depending on age, as well as with the clinico-laboratorial data to integrate them with the morphological features. Rev. Bras. Hematol. Hemoter. 2009;31(3):183-188.

Key words: Bone marrow histology; bone marrow, bone marrow histopathology.

\section{Referências Bibliográficas}

1. Bacchi CE, Almeida PCC, Franco M (Ed.). Manual de Padronização de Laudos Histopatológicos. Sociedade Brasileira de Patologia, 3.ed., Rio de Janeiro, Reichmann \& Affonso Editores, 2005.

2. Bain B, Clark D, Lampert I. Bone marrow pathology. 3.ed., Oxford, Blackwell Science, 2001.

3. Brown D, Gatter K, Natkuman Y \& Warnke R. Bone marrow diagnosis: an illustrated guide. 2.ed., Oxford, Blackwell Science, 2006.

4. Cotelingam JD. Bone marrow biopsy: interpretive guidelines for the surgical pathologist. Adv Anat Pathol. 2003;10(1):8-26.

5. Foucar K. Bone marrow pathology. 2.ed. Chicago, ASCP Press, 2001.

6. Knowles D (Ed). Neoplastic hematopathology. 2. ed. Philadelphia, Lippincott Williams \& Wilkins, 2001.

7. Naeim F. Pathology of the bone marrow. 2. ed. Baltimore, Williams \& Wilkins, 1997.

8. De Wolf-Peeters C. Bone marrow trephine interpretation: diagnostic utility and potential pitfalls. Histopathology. 1991; 18(6):489-93.

Avaliação: Editor e dois revisores externos

Conflitos de interesse: não declarado

Recebido: 15/12/2008

Aceito: 03/02/2009 